\title{
Effects of a Gamified Educational Program in the Nutrition of Children with Obesity
}

\author{
Nazaret Gómez del Río ${ }^{1}$ C Carina S. González-González ${ }^{2}$ (D) • Raquel Martín-González ${ }^{2}$. Vicente Navarro-Adelantado ${ }^{2}$. \\ Pedro Toledo-Delgado ${ }^{2}$. Francisco García-Peñalvo ${ }^{1}$
}

Received: 9 January 2019 / Accepted: 15 April 2019 / Published online: 22 May 2019

(C) Springer Science+Business Media, LLC, part of Springer Nature 2019

\begin{abstract}
Obesity is considered a global epidemic of the twenty-first century by the World Health Organization (WHO). Specifically, the Canary Islands has the highest level of this disease in Europe and $40 \%$ of children in Spain are overweight or obese. This increase is a direct result of changes in the lifestyles of the population and its nutrition. Because of this, we have designed an educational program based on motor games, active videogames and virtual learning environments to improve the long-term health of children. This article presents and analyzes the results of a study on the nutritional knowledge and adherence to the Mediterranean diet of 46 obese children aged 6 to 12 years in the Canary Islands who participated in an educational program. The study design was quasi-experimental, with two groups (experimental and control). A long-term longitudinal study (3 years) was carried out. A set of evaluation instruments was used for the different phases. The results show significant improvements between the experimental and control groups in terms of their knowledge of healthy nutrition and their adherence to the Mediterranean diet. As a main conclusion, we emphasize that a gamified educational intervention program supported by ICT helps to motivate and promote improvements in the nutrition of children.
\end{abstract}

Keywords Childhood obesity $\cdot$ Active videogames $\cdot$ Nutrition $\cdot$ Gamification

\section{Background}

Childhood is the stage of life where the habits that will be consolidated throughout our lives begin to develop.

This article is part of the Topical Collection on Education \& Training

Nazaret Gómez del Río

ngomrio@usal.es

Carina S. González-González

cjgonza@ull.edu.es

Raquel Martín-González

rmarting@ull.edu.es

Vicente Navarro-Adelantado

vnavarro@ull.edu.es

Pedro Toledo-Delgado

petode@ull.edu.es

Francisco García-Peñalvo

fgarcia@usal.es

Universidad de Salamanca, Salamanca, Spain

2 Universidad de La Laguna, San Cristóbal de La Laguna, Spain
Educating children in healthy habits from an early age is the most effective preventive measure to improve their health and quality of life. In 1998, the World Health Organization [1] warned in its annual report of the incidence of obesity as an emerging public health problem, and in 2004, it declared it a global epidemic as it affected more and more countries around the world. This organization estimates that in 2016, more than 41 million children under the age of five were overweight or obese [2]. Childhood obesity is of concern not only due to the increased prevalence of the disease in populations around the world, but to the multiple health consequences in the short, medium and long term, such as the increase in risk factors for the development of cardiovascular and metabolic diseases. There are also psychological and social problems associated with bullying and comments from their peers. In the long term, the persistence of obesity leads to an increase in disabilities or premature death. All these health problems have serious repercussions on the well-being and finances of those affected, their families and society as a whole. The Spanish Society for the Study of Obesity [3] confirms that $44.5 \%$ of Spanish children suffer from excess weight. This means that practically one in two children is overweight with respect to the growth patterns established by WHO. Only Italy and 
Cyprus surpass these figures at the European level, according to the IDEFICS study [4]. The ALADINO study of 2011 [5] notes that $26.2 \%$ of the infant population between the ages of 6 and 9 years is overweight and $18.3 \%$ is obese. In the Canary Islands, the results were $28.4 \%$ and $21.2 \%$ respectively, placing it as the Spanish autonomous community with the highest rate of childhood obesity, together with Andalusia. In its latest report [6], the results are encouraging for the Canary Islands, which found that the prevalence of overweight/obesity is five percentage points less than in the previous report. The figures, however, continue to be very high (overweight $24.3 \%$ and obesity $19.9 \%$ ). Already in 2016, the WHO [7] issued a report by the Commission to end childhood obesity which includes six recommendations for governments to reverse this global trend. Among these recommendations, we highlight the following:

- Apply comprehensive programs that encourage physical activity and reduce the sedentary habits of children and adolescents.

- Apply comprehensive programs that promote healthy school environments, health and nutrition education, and physical activity among school-age children and adolescents.

- Offer weight control services to the obese pediatric population based on family and lifestyle and with multiple components.

The World Health Organization (WHO) and other international organizations (such as the World Heart Federation, the International Diabetes Federation, among others) have defined strategies in an effort to contain high levels of obesity and physical inactivity. The general guidelines they establish rely on changing food types to reduce fat and caloric intake and increasing physical activity in the individual [8].

However, autonomous motivation is especially important for adherence to change, but despite the knowledge that lifestyle change is the most effective method for long-term weight management, adherence to exercise and physical activity can be difficult to maintain $[9,10]$. In children, the reasons for ceasing physical activity are related mainly to the difficulty in adapting to schedules, the refusal to adhere to the routine, dissatisfaction with the results, etc. [11]. Therefore, it is necessary to work not only with people affected by obesity but also to educate their relatives, since it is in the family environment where lifestyles are acquired and perpetuated. It is families that motivate change by using all the tools available to help loved ones adhere to treatments. Likewise, healthy living habits must begin to work from childhood. For children, play is a natural way of learning and can be an excellent strategy to apply in educational intervention programs. Technology also provides very useful tools to support children in their games and education. In this sense, we have designed a gamified educative program using technologies, such as exergames, sensors, apps and virtual platforms, to support health professionals for ambulatory treatment of the obesity in children.

This intervention program was designed, conducted, supervised and analyzed by professional researchers in the areas of Health (Medicine, Physiotherapy, Nursing, Psychology, Physical Education and Sports), Education and Computer Science [12]. Each area of this study focused on analyzing different characteristics of the intervention. In this study we will focus specifically on ascertaining the knowledge and eating habits of children before and after the intervention with our program.

RQ1. How does the educational intervention program influence children's knowledge of healthy eating?

RQ2. Is it possible to effect a change in the long-term eating habits of children through a gamified educational intervention program?

Below we present the study design, its main results, a discussion of our findings and the conclusions.

\section{Related works}

There are different studies on educational programs that prove the efficacy of caloric expenditure associated with the use of exergames [13-17], as well as the effectiveness of using technologies and gamification with children to promote healthy habits in the short term $[18,19]$. But there are few studies in the literature that evaluate the real effectiveness of using videogames as a means to promote long-term physical activity among children and adolescents, and very few that focus on their use as part of treating obese children, probably because it is a relatively new phenomenon $[20,21]$.

Also, in relation to the world of videogames and their use as an application to promote healthy living habits, there are several related examples, such as Let's Move! (To move!) [22], a comprehensive program created by Michael Obama in 2010 to prevent and treat childhood obesity, which included a contest to reward the best application for child health. There are several similar applications for health, such as "Counting Carbohydrates with Lenny," a Lion that teaches children with diabetes to learn the carbohydrate content of foods [23]. Also, there are different wearable game-based technologies used to increase healthy habits in children, like LeapBand [24]. With this band the children can interact with a virtual pet, which forces them to keep moving through a series of activities and challenges, and thus encourage a healthier lifestyle. Another related example of this kind of technology is Zamzee, a program to encourage physical activity among adolescents, where the physical activity is recorded with a device (accelerometer) and a computer then calculates the amount 
of points generated, which can be exchanged for products from participating companies [25]. Another system that is very similar to the previous one was created by the company GeoPalz and is called iBitz, which seeks to encourage physical activity in children and measures the number of steps that children take by means of a pedometer. With it, children can see the steps they have taken and enter them on the website. The steps become points that can be redeemed for gifts in different portals that the parents have previously selected. In addition, the number of points collected during the day will buy a few minutes of play; when they expire, the game is closed until the child moves a little more. GeoPalz has partnered with game developers so that the child's points can be used to unlock secrets and achievements in certain games [26].

Despite the market being full of videogames and technologies to promote healthy habits, the research into the behavioral change in children undergoing a long-term treatment of this kind still poses a challenge [27]. Besides, there are very few studies on whether educational interventions on healthy habits with gamification and video games work in the long term. Taking into account previous studies, an educational program based on motor games, active video games and virtual learning environments was designed to promote a change in the long-term health lifestyles of children suffering from childhood obesity, and of their families.

\section{Material and methods}

\section{Design and participants}

The study was a mixed, quasi-experimental, longitudinal and prospective three-year study (2014-2017). It consisted of two annual phases, with the same intervention being repeated in both with different subjects. Each annual intervention phase was designed to be carried out with an experimental group and a control group, with 10-15 primary school children, all of them from the northern area of the island of Tenerife.

The inclusion criteria for the sample were age (6-12 years old); body mass index (BMI) in the 97th percentile or higher [28]; having the permission of the parents or legal guardians to participate in the study; not suffering from pathologies preventing them from participating in the study; and not having participated in another clinical trial in the last 12 months. The educational level of the parents was considered as a socioeconomic indicator and was grouped into three categories: high (university studies); medium (secondary education), and low (no education or only primary education) [29].

In Phase 1, the sample consisted of children selected from the outpatient pediatrics clinic of the University Hospital of the Canary Islands (HUC) in outpatient treatment for childhood obesity. The Experimental Group (G1) consisted of 13 obese children
( 5 boys and 8 girls) who participated in the intervention program. The Control Group (G2) was composed of 10 children ( 7 boys and 3 girls) who did NOT participate in the intervention program.

In Phase 2, because the hospital patients did not yield a large enough sample to satisfy the inclusion criteria, the participants were selected from different public education schools in the district of La Laguna. It is important to note that the public reference hospital of the children in this Phase 2 is the same hospital as in Phase 1, but some of them are not in treatment yet at the hospital. There are mainly two reasons why they are not in treatment in their hospital: a) the pediatrician in the health center has not referred the patient to the hospital because he wants to wait for the children to improve until they reach adolescence, or b) the parents reject the idea that their children have an illness (obesity). Thus, the Experimental Group (G3) consisted of 12 obese children ( 5 boys and 7 girls) who participated in the intervention program. The Control Group (G4) was composed of 11 children (4 boys and 7 girls) who did NOT participate in the intervention program.

The assignment of the participants to the experimental and control groups in both phases was not carried out randomly. Those children who were able to attend all the activities and evaluations were assigned to the experimental group, while those in the control group only attended the periodic evaluations. The experimental groups (G1, G3) and control groups $(\mathrm{G} 2, \mathrm{G} 4)$ were separated during the study because of their different recruitment contexts.

Table 1 shows the participants' details, including BMI and some demographic variables.

\section{Instruments}

The study involved the use of different instruments to analyze different data in each study area. To measure body composition and make biomedical measurements, the following were used: digital scale with height meter, lipocalipter, inextensible tape measure, BMI formula, growth curve to determine the percentiles, and blood tests were used to determine biochemical values. To analyze the emotions during the intervention, we used the Emodiana [30], an instrument that allows measuring ten basic emotions, represented using different emojis and their corresponding labels, adjusted to the language used by children ages 8 to 12 . To study the behavior and personality of children and adolescents, we selected the BASC (System for assessing the behavior of children and adolescents) (Spanish adaptation of the CRC by Reynolds and R.W. Kamphaus) [31], a multidimensional questionnaire that measures numerous aspects of the child's behavior and personality. In the self-report, the child or adolescent describes their emotions and perceptions and provides information on clinical, adaptive and general parameters. To determine the children's gaming profile, we selected the Player Profile Test [32], a questionnaire with a total of 12 questions that focus on the type of videogames that the minor plays, the hours a week spent playing, and their values and beliefs regarding videogames. 
Table 1 Participants' details

\begin{tabular}{|c|c|c|c|c|c|c|c|c|c|c|c|}
\hline \multicolumn{12}{|l|}{ Phase 1} \\
\hline G1 & Sex & Age & BMI* & School & Socio-economic level & G2 & Sex & Age & BMI* & School & Socio-economic level \\
\hline GE01 & $\mathrm{F}$ & 11 & 33,3 & Public & $\mathrm{L}$ & GC01 & M & 6 & 22,91 & Public & $\mathrm{L}$ \\
\hline GE02 & $\mathrm{F}$ & 8 & 22,16 & Public & M & $\mathrm{GC} 02$ & $\mathrm{~F}$ & 11 & 25,57 & Private & M \\
\hline GE03 & M & 10 & 26,96 & Public & $\mathrm{L}$ & GC03 & $\mathrm{F}$ & 10 & 25,42 & Public & M \\
\hline GE04 & $\mathrm{F}$ & 10 & 35,72 & Public & $\mathrm{L}$ & GC04 & M & 8 & 26,65 & Public & $\mathrm{L}$ \\
\hline GE05 & $\mathrm{F}$ & 7 & 40,32 & Public & $\mathrm{L}$ & GC05 & M & 7 & 32,85 & Public & $\mathrm{L}$ \\
\hline GE06 & $\mathrm{F}$ & 10 & 31,68 & Private & M & GC06 & $\mathrm{F}$ & 8 & 29,28 & Public & $\mathrm{L}$ \\
\hline GE07 & $\mathrm{F}$ & 6 & 21,73 & Public & M & GC07 & M & 6 & 21,3 & Public & M \\
\hline GE08 & M & 11 & 34,82 & Public & $\mathrm{L}$ & GC08 & M & 10 & 27,8 & Public & $\mathrm{L}$ \\
\hline GE09 & M & 9 & 33 & Public & M & GC9 & M & 8 & 25,78 & Public & $\mathrm{L}$ \\
\hline GE10 & $\mathrm{F}$ & 7 & 40,54 & Public & $\mathrm{L}$ & $\mathrm{GC} 10$ & M & 10 & 26,75 & Public & $\mathrm{L}$ \\
\hline GE11 & M & 11 & 31,01 & Public & $\mathrm{L}$ & & & & & & \\
\hline GE12 & M & 10 & 27,87 & Public & M & & & & & & \\
\hline GE13 & $\mathrm{F}$ & 12 & 33,46 & Public & M & & & & & & \\
\hline \multicolumn{12}{|l|}{ Phase 2} \\
\hline G3 & Sex & Age & BMI* & School & Socio-economic level & G4 & Sex & Age & BMI* & School & Socio-economic level \\
\hline GE14 & $\mathrm{F}$ & 6 & 23,68 & Public & M & GC11 & $\mathrm{F}$ & 12 & 30,63 & Public & $\mathrm{M}$ \\
\hline GE15 & $\mathrm{F}$ & 9 & 31,01 & Public & M & $\mathrm{GC} 12$ & M & 10 & 29,88 & Public & M \\
\hline GE16 & $\mathrm{F}$ & 8 & 34,94 & Public & $\mathrm{L}$ & GC13 & M & 9 & 28,1 & Public & M \\
\hline GE 17 & $\mathrm{~F}$ & 11 & 31,17 & Public & M & GC14 & M & 12 & 24,95 & Public & $\mathrm{H}$ \\
\hline GE18 & $\mathrm{M}$ & 11 & 24,67 & Public & $\mathrm{L}$ & GC15 & $\mathrm{F}$ & 11 & 30,1 & Public & $\mathrm{H}$ \\
\hline GE19 & $\mathrm{F}$ & 10 & 25,64 & Public & $\mathrm{M}$ & GC16 & M & 10 & 23,52 & Public & M \\
\hline GE20 & M & 9 & 30,13 & Public & $\mathrm{L}$ & GC17 & $\mathrm{F}$ & 12 & 27,93 & Public & M \\
\hline GE21 & $\mathrm{F}$ & 8 & 25,76 & Public & M & GC18 & F & 10 & 25,56 & Public & M \\
\hline GE22 & $\mathrm{M}$ & 11 & 23,63 & Public & M & GC19 & $\mathrm{F}$ & 8 & 24,61 & Public & M \\
\hline GE23 & $\mathrm{M}$ & 8 & 25,71 & Public & M & GC20 & $\mathrm{F}$ & 8 & 21,33 & Public & M \\
\hline GE24 & $\mathrm{F}$ & 8 & 28,65 & Public & $\mathrm{L}$ & GC21 & F & 9 & 25,17 & Public & $\mathrm{H}$ \\
\hline GE25 & M & 11 & 25,09 & Public & M & & & & & & \\
\hline
\end{tabular}

*Percentile $>=97$ according to WHO [28]

Next, we will focus on describing the questionnaire, the results of which are discussed in this article:

- Healthy diet: To determine adherence to the Mediterranean diet, the KIDMED questionnaire was selected [33] (Appendix Table 6). This test has 16 yes/no items to represent the main indicators of nutrition. Affirmative answers to those questions that have a negative connotation in relation to the Mediterranean Diet are worth -1 point, and affirmative answers to those questions that represent a positive aspect in relation to the Mediterranean Diet are worth +1 point. This index can range between -4 and 12 .

- Healthy habits in nutrition: In order to ascertain their physical activity habits and their perception of well-being, we opted for the Adaptation of the Questionnaire on physical activity/sports and health/well-being of M. Delgado and P. Tercedor [34], a 22-item questionnaire that evaluates the following categories: amount of physical activity (physical activity or sports practiced, days and hours a week, hours of inactivity, etc.), enjoyment of physical activity; self-perception of motor competence and utility of physical activity and sport; nutrition; health and personal well-being. In this study we present the results of category related to nutrition (Appendix 2).

\section{Procedure}

The procedure for this study was as follows: First, the corresponding permits and informed consent forms were requested. In phase 1, approval for the investigation was requested from the Ethics Committee of HUC, and in phase 2, authorizations were also requested from the Territorial Directorate of Education of the Government of the Canary Islands and subsequently from Management at each participating center.

Next, the study physicians conducted the search for potential participants. Once the sample was selected, an information 
letter was sent to the parents or legal guardians in which the main characteristics of the study to be carried out were detailed, ensuring the anonymity of the data and the scientific purposes of the same. During a face-to-face meeting with the parents, their questions were answered and they were asked to participate in the study, either in the experimental or control group. The study sample was confirmed once the parents or guardians who decided to participate in it signed the informed consent. Finally, the study was conducted to coincide with the corresponding academic school year (from September to June) for each annual phase. The work sessions were divided into three quarterly stages: intervention, creation of the vocational project and development of said project (Fig. 1). The evaluations carried out with the instruments described in the previous section were carried out before, during and at the end of each of the annual phases.

\section{First stage: Intervention}

The intervention consisted of a two-hour, weekly group session in person (a total of 12 sessions) (Fig. 2). In these sessions, the participants were given training activities on healthy habits and health education on obesity (60 min); traditional motor games were practiced and activities involving an active videogame with contents on healthy habits were carried out in pairs $(60 \mathrm{~min})$. All the sessions were designed from a play point of view, meaning that after the theoretical content was presented, it was reinforced with a game (using motor games and the active videogame TANGO:H [35]). Thus, each session featured a game designed specifically for this content. This was complemented with two weekly 30 -min physical activity sessions at home with a commercial video game (Wii Fit Plus). We also worked with the parents, mothers and/or guardians of the minors, who received a 90-min educational session during which three topics were discussed: healthy lifestyle habits, obesity as a disease, and false beliefs about video games. We accounted for the diversity of the geographical origins of the families (different Spanish autonomous communities, Venezuela, China, etc.) to educate them in nutritional habits. There was a good rapport and communication between the team and parents, and in order to provide support and motivation to positively influence changes in habits, ICT tools such as instant messaging services (WhatsApp), social networks (Facebook) and Google apps were used to maintain this relationship.

a) Initial training in group sessions

b) Motor play in group sessions

c) Nutritional activities in TANGO:H

d) Training with parents using Classdojo

\section{Second stage: Creation of vocational project}

This stage entailed the creation of a vocational project intended to identify healthy activities that the participants might like in their environment. This activity was supervised through a weekly videoconference session and the use of the Moodle virtual platform. Likewise, the program of activities with Wii Fit Plus continued at home with two weekly sessions lasting $30 \mathrm{~min}$ each.
Fig. 1 Stages and instruments used in each annual phase

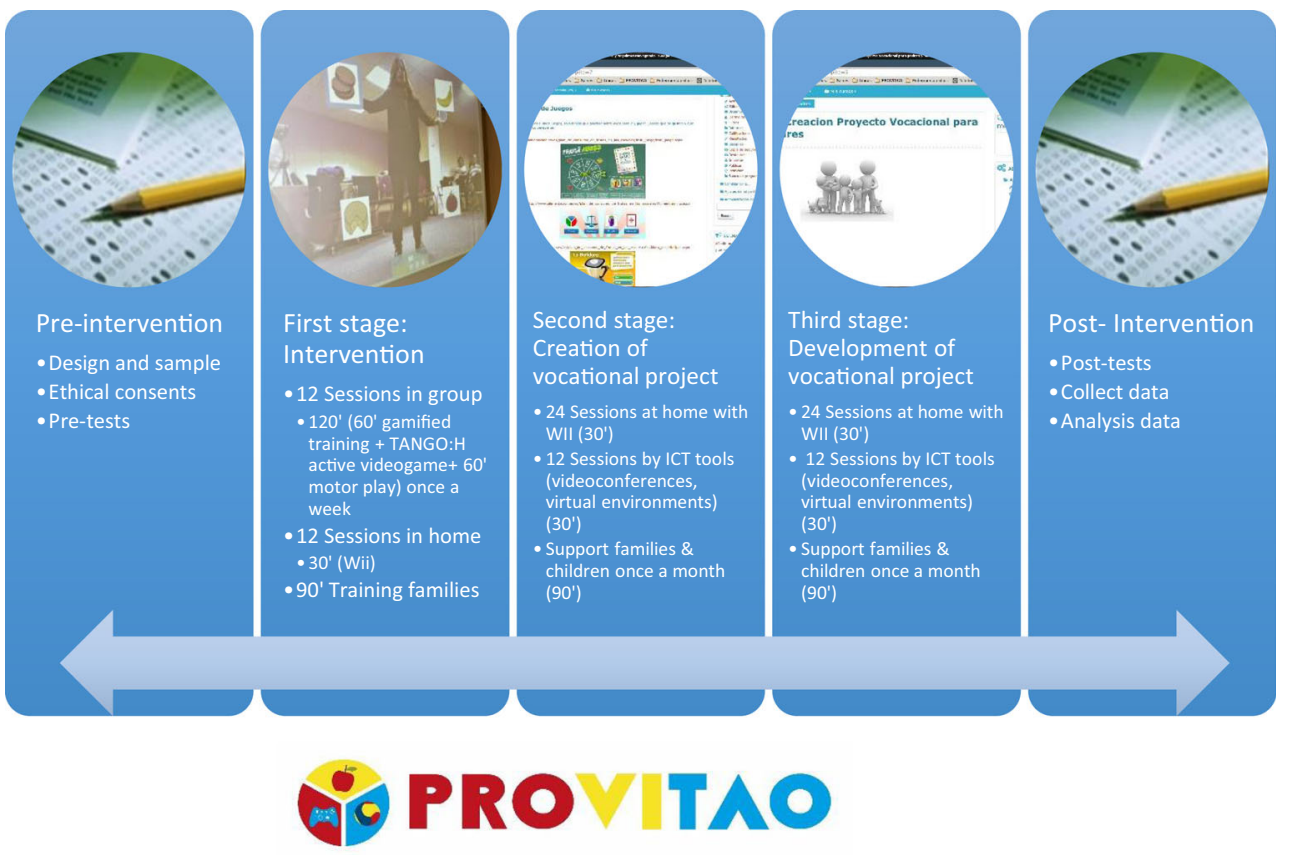


Fig. 2 Different moments and strategies used in the educational intervention. a Initial training in group sessions. b Motor play in group sessions. c Nutritional activities in TANGO:H. d Training with parents using Classdojo

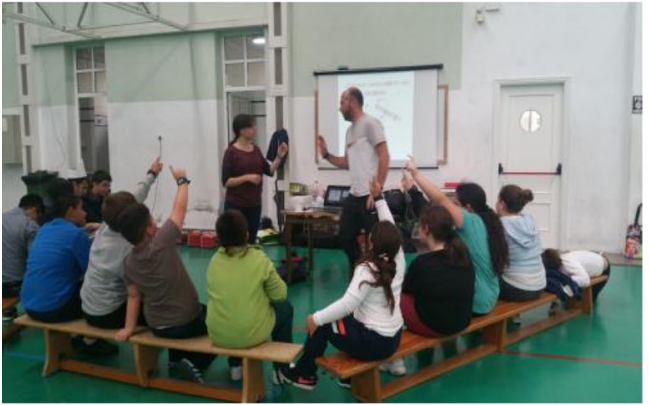

a

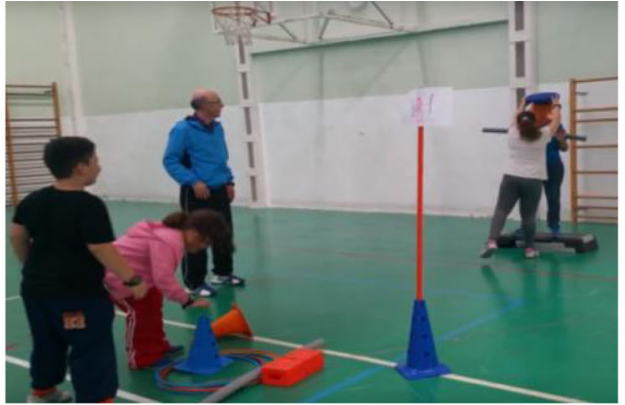

b

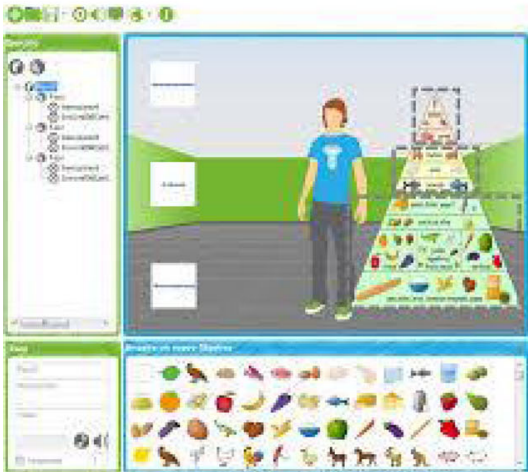

C

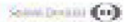

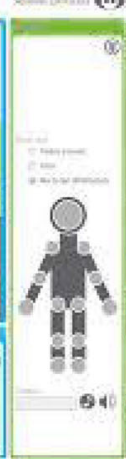

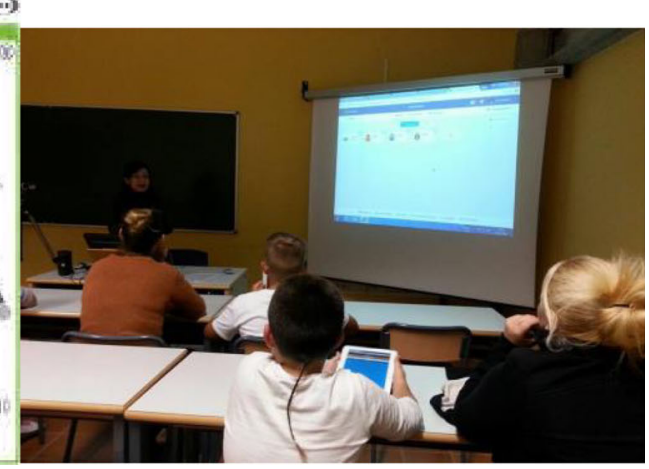

d
The periodicity of the face-to-face group sessions became monthly. These sessions lasted $2 \mathrm{~h}$ and focused on reinforcing the activities carried out throughout the week. Also done on a monthly basis were several orientation activities with the parents to support the development of their children's vocational project, as well as to answer questions regarding the use of the different ICT tools (videoconference and Moodle platform).

\section{Third stage: Development of vocational project}

This last stage required each participant to develop their own vocational project on healthy activities and provided support the children as they started their new activities. To this end, individual, home and continuous care was offered, supported by ICT (videoconferences and the Moodle platform, and Classdojo for follow-up). In addition, the two weekly athome physical activity sessions with the Wii Fit Plus were continued, as was the counseling for parents on the development of the vocational project. We also gave talks and workshops on healthy lifestyle habits to students from 3rd to 6th grade in primary schools, showing them how to use TANGO:H and other technological tools (Kahoot!) (Fig. 3).

In each phase of the study, we collected data for that year for further analysis prior to, during and at the end of the intervention.

\section{Results}

\section{Knowledge of nutrition throughout the study}

In this section we analyze the participants' answers involving their knowledge of healthy nutrition. In all cases, higher scores indicate better habits, knowledge and satisfaction. All the variables involved in these analyses exhibit a normal distribution, as per the Kolmogorov-Smirnov test. The comparison of the means of the two groups in the baseline indicates that both presented similar scores at the beginning of the study in the indices studied (Table 2).

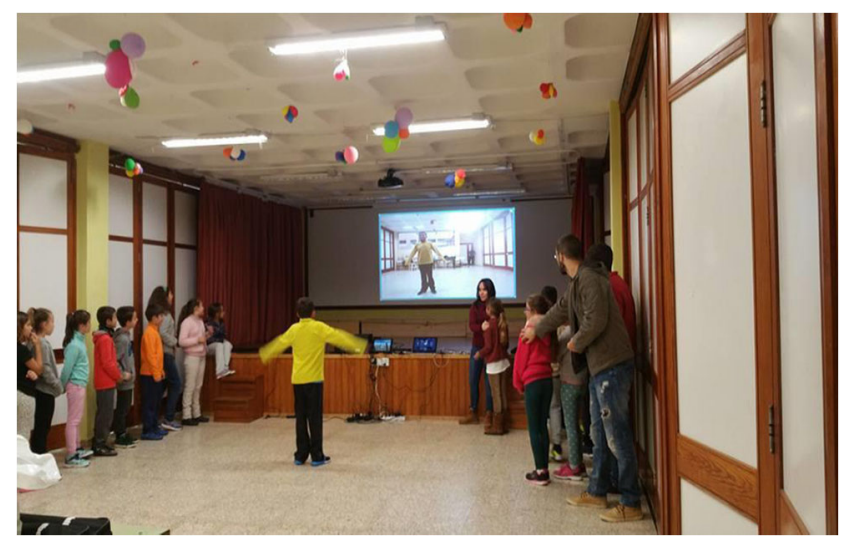

Fig. 3 Use of active videogames in schools 
For each indicator, the analysis of repeated measurements is performed, with a group as an inter-subject factor and an intra-subject factor with three levels that we have called "Tracking" (Table 3). Each level is defined by one phase of the intervention: the baseline (measurements taken before the intervention began), the immediate followup (evaluation done at the end of the face-to-face intervention phase), and the long-term follow-up (evaluation done after finishing the intervention with the children and removing the follow-ups). When the sphericity of the variance-covariance matrices is not met, the epsilon correction is applied using the Greenhouse-Geisser method. In the case of the main effects of the intra-subject factor, a posteriori analysis is performed with the Bonferroni adjustment; likewise, if in the analysis of the main effects the criterion of homogeneity of the variances is not met, the robust Welch test is performed.

The interaction between the Tracking and Group factor is not significant $(\mathrm{F}(2.50)=2582, p=.086, \eta 2 \mathrm{p}=.094$, $P=.492$ ), there is no significant Group effect ( $\mathrm{F}$ $(1.25)=0.503, p=.485, \eta 2 \mathrm{p}=.020, P=.105)$. On the other hand, there is a significant follow-up factor effect ( $\mathrm{F}$ $(2.50)=28.647, p=.000, \eta 2 p=.532, P \geq 0.999)$. When looking at the analysis by pairs with the Bonferroni adjustment, we find that the scores in the long-term followup are significantly different from those of the baseline $(\mathrm{t}$ $(23)=7.002, p \leq .001 ; \mathrm{d}=1.2)$ and those of the immediate follow-up ( $\mathrm{t}(23)=6.234 ; p \leq .001 ; \mathrm{d}=0.99)$. Analyzing the evolution of the means (See Fig. 4), and considering the two groups together, shows that, in both cases, the highest means for the knowledge variable are given in the long term.

The graph representing the means indicates that, although the interaction between the Tracking and Group factor is not significant, there may be interaction between the baseline and the immediate follow-up, that is, the one done just after the face-to-face intervention phase. Therefore, this phase will be analyzed independently. In this case, the variance-covariance matrix does not exhibit a sphericity pattern, so the Epsilon correction will be done using the Greenhouse-Geisser method. The interaction between the immediate follow-up factor and the Group is significant $(\mathrm{F}(1.00,31.00)=6.911, p=.013, \eta 2 \mathrm{p}=.182$, $P=.721)$, as is the main effect of the immediate follow-up

Table 2 Mean and group (standard deviations) and statistics of the difference of means of the scores in the questionnaires of the participants in the baseline

\begin{tabular}{lllllll}
\hline & $\begin{array}{l}\text { Control } \\
N=20\end{array}$ & $\begin{array}{l}\text { Experimental } \\
N=25\end{array}$ & $\mathrm{~F}(1.43)$ & $\mathrm{p}$ & $\eta 2 \mathrm{p}$ & $\mathrm{P}$ \\
\hline Nutrition & $27.00(3.64)$ & $26.40(2.66)$ & 0.41 & .52 & 01 & .10 \\
\hline
\end{tabular}

Bonferroni adjustment
Table 3 Means and (standard deviations) of the indices of the questionnaires reported by the two groups of minors in the follow-up evaluations

\begin{tabular}{|c|c|c|c|c|}
\hline & \multicolumn{2}{|l|}{ Immediate } & \multicolumn{2}{|l|}{ Long term } \\
\hline & $\begin{array}{l}\text { Control } \\
N=16\end{array}$ & $\begin{array}{l}\text { Experimental } \\
N=17\end{array}$ & $\begin{array}{l}\text { Control } \\
N=16\end{array}$ & $\begin{array}{l}\text { Experimental } \\
N=15\end{array}$ \\
\hline Nutrition & $27.00(2.88)$ & $28.71(2.62)$ & $29.56(2.50)$ & $30.87(2.95)$ \\
\hline
\end{tabular}

Bonferroni adjustment

factor $(\mathrm{F}(1.00,31.00)=6.911, p=.013, \eta 2 \mathrm{p}=.182$, $P=.721)$, but not of the Group factor $(\mathrm{F}(1.31)=0.215$, $p=.646, \eta 2 \mathrm{p}=.007, P=.073)$.

As shown in Fig. 4, when we averaged the scores of the two groups, the means in the follow-up exceeded those of the baseline; on the other hand, the interaction observed and the review of the means indicates that the scores of each group describe a different evolution between the baseline and immediate follow-up.

\section{Adherence to the Mediterranean diet}

In this section we analyze the responses of the children in the questionnaire on the quality of the Mediterranean diet - KIDMED. We analyze the data of the pretest and the immediate posttest (after the face-to-face intervention). As the data show, at the beginning both groups had an average KIDMED index of 7 (average adherence). However, after the intervention, the experimental group showed a slight improvement in this index, while in the control group it declined. These differences in the KIDMED index are not significant. Therefore, we decided to provide the following tables where each item in the KIDMED questionnaire is shown as a percent for both the control group and the experimental group. These tables show significant differences in vegetable intake (one or more), and the consumption of fish, pasta and cereals. Also

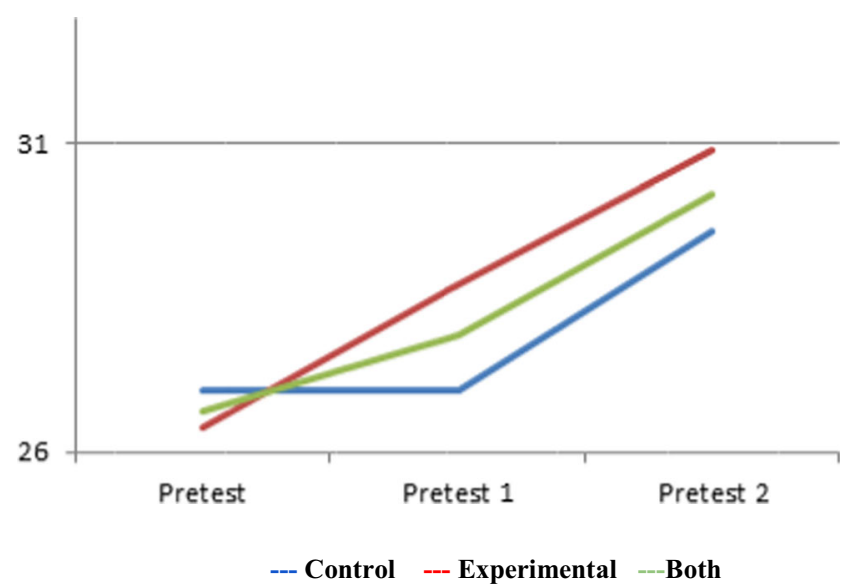

Fig. 4 Knowledge about nutrition during the study 
Table 4 KIDMED index for different times and groups

\begin{tabular}{lllll}
\hline Index & Experimental & Experimental \\
KIDMED & group & group & $\begin{array}{l}\text { Control } \\
\text { group }\end{array}$ & $\begin{array}{l}\text { Control } \\
\text { group }\end{array}$ \\
& $\begin{array}{l}\text { Pre } \\
\text { Min }=5.00 /\end{array}$ & $\begin{array}{l}\text { Min }=5.00 / \\
\text { Pre }\end{array}$ & $\begin{array}{l}\text { Min }=4.00 / \\
\text { Min }=5.00 /\end{array}$ \\
& Max $=11.00$ & $\operatorname{Max}=10.00$ & $\operatorname{Max}=11.00$ & Max $=10.00$ \\
\hline Mean & 7.67 & 7.75 & 7.11 & 6.78 \\
\hline
\end{tabular}

significant is the number of children who have stopped eating industrial pastries for breakfast.

Regarding the impact of the program on dietary habits, as Table 4 shows, in the experimental group, the KIDMED index exhibits a slight improvement that is not significant, while the control group sees a worsening in its KIDMED index that is significant.

In Table 5 below, we can see represented in percentages the items according to the group to which they belong and the time when all the participants were evaluated.

\section{Relationship between results}

Regarding the results on healthy habits [34] in particular, we presented the results on the "nutrition" category. The results show a slight improvement in the GE (baseline $=26.40$; post immediate intervention $=28$; long-term post intervention $=$ 30.87 ) compared with the $\mathrm{GC}$ (baseline $=27$; post immediate intervention $=27$; long-term post intervention $=29.56$ ), and as Fig. 4 shows, a better evolution in GE than GC.

About the KIDMED [33], the results show a small improvement in the GE index (pre-test $=7.67$; post-test $=7.75$ ) and a minor worsening in the GC index (pre-test $=7.11$; post- test $=6.78$ ). Also, analyzing all the items that comprise the KIDMED test according to the group to which they belonged, it became clear that there were improvements in the experimental group involving the consumption of vegetables (pretest $=91.6$; post-test $=100$ ), fish (pre-test $=66.6$; post-test $=$ 83.3), or cereals for breakfast (pre-test $=83.3$; post-test $=$ 91.6), and that all of them stopped eating industrial pastries for breakfast (pre-test $=8.3$; post-test $=0$ ). In contrast, the control group stopped having vegetables regularly (pre-test $=$ 77.7; post-test $=55.5$ ), and also exhibited worse indicators related to industrial bakery and sweets (pre-test $=0$; post-test $=$ 11.1). Then, the " $t$ " test was performed for related samples, which allowed us to confirm whether or not there were significant differences between the pretest and the posttest both in the experimental group and in the control group. In both cases, we must accept that the measure in the population in both the experimental group (0.72) and the control group (0.563) is the same, and no significant differences were found when the values were greater than 0.5 . Subsequently, the " $t$ " test was done for independent samples, relating first the pretest in the experimental and control groups. This did not reveal any significant differences in the questionnaire between the experimental and control groups (0.54). Thus, we started with a sample with homogeneous measurements in relation to the quality of the Mediterranean diet, but after the intervention, we found significant differences in the post-test of the experimental and control groups (0.23). We can thus affirm that the means corresponding to the two groups are equal, meaning that the children who participated in the experimental group managed to improve the quality of their diet.

To summarize the results, we observed a slight improvement in the GE's knowledge of healthy nutrition and a better adherence to the Mediterranean diet compared to the GC, both in the immediate post intervention and in the long term.

Table 5 Results by item of the KIDMED test

\begin{tabular}{|c|c|c|c|c|}
\hline KIDMED test & $\begin{array}{l}\text { Experimental group } \\
\text { Pre }\end{array}$ & $\begin{array}{l}\text { Experimental group } \\
\text { Post }\end{array}$ & $\begin{array}{l}\text { Control group } \\
\text { Pre }\end{array}$ & $\begin{array}{l}\text { Control group } \\
\text { Post }\end{array}$ \\
\hline Has a fruit or fruit juice every day & 66.6 & 66.6 & 77.7 & 66.6 \\
\hline Has a second fruit every day & 25.0 & 0.0 & 33.3 & 33.3 \\
\hline Has fresh or cooked vegetables regularly once a day & 91.6 & 100.0 & 77.7 & 55.5 \\
\hline Has fresh or cooked vegetables more than once a day & 41.6 & 25.0 & 11.1 & 11.1 \\
\hline Consumes fish regularly (at least $2-3 /$ week) & 66.6 & 83.3 & 77.7 & 66.6 \\
\hline Goes $>1$ / week to a fast food restaurant (hamburger) & 0.00 & 0.0 & 0.0 & 0.0 \\
\hline Likes pulses and eats them $>1$ /week & 91.6 & 83.3 & 77.7 & 66.6 \\
\hline Consumes pasta or rice almost every day ( 5 or more per week) & 25.0 & 50.0 & 33.3 & 33.3 \\
\hline Has cereals or grains (bread, etc.) for breakfast & 83.3 & 91.6 & 77.7 & 77.7 \\
\hline Consumes nuts regularly (at least $2-3 /$ week) & 16.6 & 16.6 & 33.3 & 55.5 \\
\hline Uses olive oil at home & 91.6 & 91.6 & 100.0 & 100.0 \\
\hline Skips breakfast & 0.0 & 0.0 & 0.0 & 11.1 \\
\hline Has a dairy product for breakfast (yogurt, milk, etc.) & 100.0 & 100.0 & 88.8 & 88.8 \\
\hline Has commercially baked goods or pastries for breakfast & 8.3 & 0.0 & 22.2 & 11.1 \\
\hline Has two yogurts and/or some cheese (40 g) daily & 75.0 & 66.6 & 44.4 & 55.5 \\
\hline Eats sweets and candy several times every day & 0.0 & 0.0 & 0.0 & 11.1 \\
\hline
\end{tabular}




\section{Discussion and conclusions}

Throughout the phases of the study, we observed a significant improvement in both groups' knowledge of healthy eating, reaching higher levels in the long term than in the two previous evaluations. On the one hand, this common drift may be reflecting the benefits of formal, family and health education, which was available to both groups in the community and whose access was promoted by the Project. By focusing only on the times before and immediately after the face-to-face intervention, we found a different trend in the scores of both groups. Looking at the means, we see how the experimental group's knowledge of healthy eating is higher than the baseline, while that of the control group remains stable. From that moment, the knowledge of the two groups increases with a similar profile, evolving in parallel. Having participated in the experimental group seems to be a benefit, since the gap in the knowledge gained by the experimental group after the face-to-face intervention remains in the long term. Likewise, a significant improvement was observed in adherence to the Mediterranean Diet (MD) of the experimental group compared to the control group. In addition, we observed that the control group worsened in some items compared to the experimental group. This result is important because the MD is traditionally a model of heart-healthy food, one that is characterized by a high consumption of vegetables, legumes, fruits, nuts and cereals and, especially, olive oil. The MD also includes recipes and cooking methods. It is probably one of the healthiest dietary models that currently exists. Numerous epidemiological studies [36-38] highlight the beneficial effects of this type of diet in combatting cardiovascular diseases, diabetes, certain tumors and other pathologies associated with oxidative stress. In this sense, the MD is related to a higher life expectancy and a lower incidence of chronic-degenerative diseases [39], evidencing that a small increase in the rate of adherence to the MD leads to a significant reduction in the risk of mortality and in the incidence of these diseases [40]. This study, however, presents a series of limitations. We must bear in mind that we had a sample of 46 participants during the two phases; however, the participants' withdrawal from the study over the months meant the loss of data. In addition, the participants came from different social contexts so we had to adapt the recommendations on eating habits and physical activities to the economic possibilities of each family. Moreover, in phase 1, the participants attended private and public schools, so there was no homogeneity of knowledge. Finally, the children had different leisure interests and attention spans, so we had to work quickly to create a circle of trust among the participants.

Finally, although it was not the goal of this paper to describe the general intervention program and all its results, we will highlight its strong points:

- The PROVITAO project has developed a gamified educational program for healthy habits, based on active video games and motor games. It has created and validated a frame of reference for intervention, monitoring and emotional, biomedical, interactive, social, psychological and educational evaluation, based on games, applied to the treatment of childhood obesity and to preventing associated complications. It has also produced various technological products (exergames, serious games, webapps, sensory libraries, wearables, etc.).

- The program developed consists of a plan of activities specifically designed around healthy habits with motor games, commercial video games (Wii Fit Plus and apps), and internally-developed games such as TANGO:H, which can be presented at home and in group face-toface sessions. PROVITAO was applied to a total of 46 children with childhood obesity and their caregivers during the school year, in two phases.

- The research design used was of the quasi-experimental mixed type, with two control groups and two experimental groups.

- The research group has participated in various activities at the local level (talks in schools, conferences, workshops, etc.) to promote healthy habits.

- This study was carried out over 3 years, from 2014 to 2017, thanks to the joint work done by a multidisciplinary team of professionals in the areas of Physical Education, Psychology, Pedagogy, Health Sciences and Computer Science who designed, supervised, executed and studied the program proposed in this article.

Despite the limited scope of this study, it has great potential to gain knowledge on the childhood population with obesity because:

- It takes place in one of the Autonomous Communities with the highest rates of obesity in Spain and in Europe.

- It provides information on the healthy habits of an intercultural population.

- In involves an age group where healthy living habits can be more easily promoted.

- It educates and raises awareness in the entity that is ultimately responsible for the eating habits and physical activity of children: the family [41].

- It is one of the first programs to use gamification tools focused on non-formal educational learning involving obesity and lifestyle and their long-term assessment.

Acknowledgements We would like to thanks to the children and their families who have participated in this study. Also, we gratefully acknowledge the researchers and collaborators of PROVITAO from different areas: Health (Carmela Quirce González, Norberto Marrero Gordillo, Honorio Armas Ramos, Mariana E. Cairós González, Josue Monzón Diaz, Mercedes Murray), Technology (Yeray del Cristo Barrios Fleitas, Alberto Mora Carreño, Belén Armas Torres, Vanesa Muñoz Cruz, Lorenzo Moreno Ruiz, Jesús Rodríguez Alamo, Miguel A. Padrón, 
Niobe Jerez, Belén Armas Torres, Pablo V. Torres Carrion) and Education (Luis Navarro Campillo, Elisenda Espino Espino, Silvia Vera González, Isa Neves). Besides, we thank the Canary Islands Government Education Counseling and the schools and teachers who collaborated with the project.

Funding This study was funded by "Fundación Caja Canarias" (grant number OBE05).

\section{Compliance with ethical standards}

Conflict of interest Authors declares that they have no conflict of interest.

Ethical approval All procedures performed in studies involving human participants were in accordance with the ethical standards of the research committee of "Hospital Universitario de Canarias" and with the 1964 Helsinki declaration and its later amendments or comparable ethical standards.

Informed consent Informed consent was obtained from all individual participants included in the study.

\section{Appendix 1}

Table 6 KIDMED [20]

Test to assess adherence to the Mediterranean Diet

\begin{tabular}{ll}
\hline KIDMED test & Scoring \\
\hline Has a fruit or fruit juice every day & +1 \\
Has a second fruit every day & +1 \\
Has fresh or cooked vegetables regularly once a day & +1 \\
Has fresh or cooked vegetables more than once a & +1 \\
$\quad$ day & +1 \\
Consumes fish regularly (at least 2-3/week) & -1 \\
Goes $>1$ / week to a fast food restaurant (hamburger) & +1 \\
Likes pulses and eats them $>1 /$ week & +1 \\
Consumes pasta or rice almost every day (5 or more & +1 \\
$\quad$ per week) & +1 \\
Has cereals or grains (bread, etc) for breakfast & +1 \\
Consumes nuts regularly (at least 2-3/week) & +1 \\
Uses olive oil at home & +1 \\
Skips breakfast & -1 \\
Has a dairy product for breakfast (yogurt, milk, etc) & +1 \\
Has commercially baked goods or pastries for & -1 \\
$\quad$ breakfast & \\
Has two yogurts and/or some cheese (40 g) daily & \\
Eats sweets and candy several times every day & \\
KIDMED index & Adherence to Med \\
& Diet \\
Score $<=3$ points & Poor \\
Score 4-7 points & Medium \\
Score $>=8$ points & High \\
\hline
\end{tabular}

[20] Adapted from: Serra-Majem, L.; Ribas, L.; García, A.; PérezRodrigo, C.; Aranceta, J. Nutrient adequacy and Mediterranean Diet in Spanish school children and adolescents. Eur J Clin Nutr. 2003; 57, 35-9

\section{Appendix 2}

\section{Health questionnaire [21]}

(*) Category Nutrition: [the HIGHER the score, the BETTER the knowledge of eating habits]

-Indicate which of these foods you consider to be more or less healthy.

\begin{tabular}{lll}
\hline & Healthy & Unhealthy \\
Coffee & 1 & 0 \\
Milk or shakes & 1 & 0 \\
Refreshments & 0 & 1 \\
Packaged juices & 0 & 1 \\
Natural juices & 1 & 0 \\
Hamburgers or sausages & 0 & 1 \\
Sausages such as chorizo, mortadella, sausage ... & 0 & 1 \\
Homemade or bagged potato chips & 0 & 1 \\
Cakes and sweets & 0 & 1 \\
Vegetables & 1 & 0 \\
Fruit & 1 & 0 \\
Candies (candies ...) & 0 & 1 \\
Nuts (seeds, peanuts, nuts ...) & 1 & 0 \\
Legumes (chickpeas, lentils ...) & 1 & 0 \\
Butter or margarine & 0 & 1 \\
Yogurt & 1 & 0 \\
Fresh cheese & 1 & 0 \\
Yellow cheese & 0 & 1 \\
Chicken or turkey & 1 & 0 \\
Meat with a lot of fat & 0 & 1 \\
Fish & 1 & 0 \\
Eggs or omelet & 1 & 0 \\
\hline
\end{tabular}

-What foods should we consume daily, weekly and monthly?

\begin{tabular}{llll}
\hline & Daily & Weekly & Monthly \\
Eggs & 0 & 1 & 0 \\
Fish & 0 & 1 & 0 \\
Olive oil & 1 & 0 & 0 \\
Sweets & 0 & 0 & 1 \\
Vegetables & 1 & 0 & 0 \\
Cheese, milk, yogurt & 1 & 0 & 0 \\
Cereals, bread, pasta, rice, potatoes ... & 1 & 0 & 0 \\
Poultry & 0 & 1 & 0 \\
Meat & 0 & 0 & 1 \\
Fruits & 1 & 0 & 0 \\
Beans, legumes and nuts & 1 & 0 & 0 \\
\hline
\end{tabular}

-Overall, do you think your diet is healthy?

- No [0]

- A little [1]

- Enough / Could be improved [2]

- Very [3]

- I do not know [0] 


\section{References}

1. Dieta, N., and de Enfermedades Crónicas, P. (2003). Informe de una Consulta Mixta de Expertos OMS/FAO. OMS, Serie de Informes Técnicos, 916:1-152.

2. Organización Mundial de la Salud. (2018). Obesidad y sobrepeso. Available in: https://www.who.int/es/news-room/fact-sheets/detail/ obesity-and-overweight.

3. Campillo, J. E., Carmena, R., Casanueva, F., Durán, S., FernándezSoto, M. L., Formiguera, X., and Ríos, M. S., Consenso SEEDO'2000 para la evaluación del sobrepeso y la obesidad y el establecimiento de criterios de intervención terapéutica. Med. Clin. (Barc.) 115:587-597, 2000.

4. Ahrens, W., Bammann, K., Siani, A., Buchecker, K., De Henauw, S., Iacoviello, L., ... and Molnár, D. The IDEFICS cohort: design, characteristics and participation in the baseline survey. Int. J. Obes. 35(S1): S3, 2011.

5. Ortega, R. M., López-Sobaler, A., Aparicio, A., González, L. G., Navia, B., and Perea, J. M., Estudio ALADINO 2013: Estudio de Vigilancia del Crecimiento, Alimentación, Actividad Física, Desarrollo Infantil y Obesidad en España 2013. Madrid: Agencia Española de Consumo, Seguridad Alimentaria Y Nutrición. Ministerio de Sanidad, Servicios Sociales e Igualdad, 2014.

6. Estudio ALADINO 2015: Estudio de Vigilancia del Crecimiento, Alimentación, Actividad Física, Desarrollo Infantil y Obesidad en España 2015. Agencia Española de Consumo, Seguridad Alimentaria y Nutrición. Ministerio de Sanidad, Servicios Sociales e Igualdad. Madrid, 2016. Available in: http://www. aecosan.msssi.gob.es/AECOSAN/docs/documentos/nutricion/ observatorio/Estudio ALADINO 2015.pdf.

7. Organización Mundial de la Salud, and de la Salud, A. M. Informe de la Comisión para acabar con la obesidad infantil: Informe de la Directora General (No. A69/8). Organización Mundial de la Salud, 2016.

8. de la Torre Díez, I., Garcia-Zapirain, B., López-Coronado, M., Rodrigues, J. J., and del Pozo Vegas, C., A new mHealth app for monitoring and awareness of healthy eating: Development and user evaluation by spanish users. J. Med. Syst. 41(7):109, 2017.

9. Khaylis, A., Yiaslas, T., Bergstrom, J., and Gore-Felton, C., A review of efficacious technology-based weight-loss interventions: Five key components. Telemedicine Journal 16(9):931-938, 2010.

10. Lewis, B. A., Napolitano, M. A., Buman, M. P., Williams, D. M., and Nigg, C. R., Future directions in physical activity intervention research: Expanding our focus to sedentary behaviors, technology, and dissemination. J. Behav. Med. 40(1):112-126, 2017.

11. Nogueira, T. F. D., and Zambon, M. P., Reasons for non-adherence to obesity treatment in children and adolescents. RPPED 31(3): 338-343, 2013.

12. del Río, N. G., González, C. S. G., González, R. M., Adelantado, V. N., Delgado, P. T., and Fleitas, Y. B. Gamified educational programme for childhood obesity. In: Global Engineering Education Conference (EDUCON), 2018 IEEE (pp. 1962-1668). IEEE, 2018.

13. González-González, C. S., del Río, N. G., and Navarro-Adelantado, $\mathrm{V}$., Exploring the benefits of using gamification and videogames for physical exercise: A review of state of art. IJIMAI 5(2), 2018.

14. Lanningham-Foster, L., Foster, R. C., McCrady, S. K., Jensen, T. B., Mitre, N., and Levine, J. A., Activity-promoting video games and increased energy expenditure. J. Pediatr. 154(6):819-823, 2009.

15. Mellecker, R. R., and McManus, A. M., Energy expenditure and cardiovascular responses to seated and active gaming in children. Arch. Pediatr. Adolesc. Med. 162(9):886-891, 2008.

16. Canabrava, K. L., Faria, F. R., Lima, J. R. D., Guedes, D. P., and Amorim, P. R., Energy expenditure and intensity of active video games in children and adolescents. Res. Q. Exerc. Sport 89(1):4756, 2018.

17. Bock, B. C., Dunsiger, S. I., Ciccolo, J. T., Serber, E. R., Wu, W. C., Tilkemeier, P. et al., Exercise videogames, physical activity, and health: Wii heart fitness: A randomized clinical trial. Am. J. Prev. Med., 2019.

18. González, C. S., Gómez, N., Navarro, V., Cairós, M., Quirce, C., Toledo, P., and Marrero-Gordillo, N., Learning healthy lifestyles through active videogames, motor games and the gamification of educational activities. Comput. Hum. Behav. 55:529-551, 2016.

19. Pernencar, C., Sousa, P., Frontini, R., Martinho, R., Runte, D., Mendes, D., and Carvalho, M., Planning a health promotion program: Mobile app gamification as a tool to engage adolescents. Procedia Comput. Sci. 138:113-118, 2018.

20. Hernández, C., Paz-Zulueta, M., Parás-Bravo, P., Pellico, A., Sarabia, R., and Santibáñez, M., Impact of active video games on body mass index in children and adolescents: Systematic review and meta-analysis evaluating the quality of primary studies. Rev. Epidemiol. Sante Publique 66:S322, 2018.

21. Rudella, J. L., and Butz, J. V., Using interactive video games to enhance physical activity among children. In: Physical activity and health promotion in the early years. Cham: Springer, 2018, 93-112.

22. Miller, G. F., Sliwa, S., Michael, S., Lee, S., Burgeson, C., Krautheim, A. M. et al., Evaluation of Let's move! Active schools activation grants. Prev. Med. 108:36-40, 2018.

23. My health apps: Available online: http://myhealthapps.net/app/ details/221/carb-counting-with-lenny

24. Cvetković, B., Janko, V., Gradišek, A., Luštrek, M., Kajtna, T., and Strumbelj, B. Mobile application to stimulate physical activity in schoolchildren. In: 2016 12th international conference on intelligent environments (IE) (pp. 206-209). IEEE, 2016.

25. Schuman, A. J., Improving patient care: Smartphones and mobile medical devices: Mobile medical gadgetry is in its infancy, yet these devices can help you motivate pediatric patients and their parents to adopt healthier lifestyles. Contemp. Pediatr. 30(6):33-38, 2013.

26. Johnsen, K., Ahn, S. J., Moore, J., Brown, S., Robertson, T. P., Marable, A., and Basu, A., Mixed reality virtual pets to reduce childhood obesity. IEEE Trans. Vis. Comput. Graph. 20(4):523530, 2014.

27. Guy, S., Ratzki-Leewing, A., and Gwadry-Sridhar, F., Moving beyond the stigma: Systematic review of video games and their potential to combat obesity. Int. J. Hypertens. 2011, 2011.

28. WHO Multicentre Growth Reference Study Group, WHO Child Growth Standards based on length/height, weight and age. Acta Paediatr Supplement 450:76, 2006.

29. Galobardes, B., Shaw, M., Lawlor, D. A., Lynch, J. W., and Smith, G. D., Indicators of socioeconomic position (part 1). J. Epidemiol. Community Health 60(1):7-12, 2006.

30. González-González, C. S., Cairós-González, M., and NavarroAdelantado, V. EMODIANA: Un instrumento para la evaluación subjetiva de emociones en niños y niñas. In: Actas del XIV Congreso Internacional de Interacción Persona-Ordenador. (Vol. 2, No. 5112.2169), 2013. https://doi.org/10.13140/RG.

31. Reynolds, C. R., Kamphaus, R. W., and Marqués, J. G., BASC: Sistema de evaluación de la conducta en niños y adolescentes: Manual. TEA, 2004.

32. Alfageme González, M. B., and Sánchez Rodríguez, P. A., Un instrumento para evaluar el uso y las actitudes hacia los videojuegos. Pixel-Bit 20:17-32, 2003.

33. Serra-Majem, L., Ribas, L., Ngo, J., Ortega, R. M., García, A., Pérez-Rodrigo, C., and Aranceta, J., Food, youth and the Mediterranean diet in Spain. Development of KIDMED, Mediterranean diet quality index in children and adolescents. Public Health Nutr. 7(7):931-935, 2004. 
34. Delgado, M., and Tercedor, P., Estrategia de intervención en educación para la salud desde la educación. INDE publicaciones, 2002.

35. González-González, C. S., Toledo-Delgado, P., Padrón, M., Santos, E., and Cairos, M., Including gamification techniques in the design of TANGO:H platform. J. Teknol. 63:77-84, 2013.

36. De la Montaña, J., Castro, L., Cobas, N., Rodríguez, M., and Míguez, M., Adherencia a la dieta mediterránea y su relación con el índice de masa corporal en universitarios de Galicia. Nutr. Clin. Diet. Hosp. 32(3):72-80, 2012.

37. Trichopoulou, A., Bamia, C., and Trichopoulos, D., Mediterranean diet and survival among patients with coronary heart disease in Greece. Arch. Intern. Med. 165(8):929-935, 2005.

38. Martínez-González, M. Á., Corella, D., Salas-Salvadó, J., Ros, E., Covas, M. I., Fiol, M., ... and Lapetra, J. (2010). Cohort profile:
Design and methods of the PREDIMED study. Int. J. Epidemiol., 41(2), 377-385.

39. Sofi, F., Cesari, F., Abbate, R., Gensini, G. F., and Casini, A., Adherence to Mediterranean diet and health status: Meta-analysis. BMJ 337:a1344, 2008.

40. Sofi, F., Abbate, R., Gensini, G. F., and Casini, A., Accruing evidence on benefits of adherence to the Mediterranean diet on health: An updated systematic review and meta-analysis. Am. J. Clin. Nutr. 92(5):1189-1196, 2010.

41. Núñez del Campo, L. Marketing y hábitos alimentarios en la población infanto-juvenil española. p. 109, 2018.

Publisher's Note Springer Nature remains neutral with regard to jurisdictional claims in published maps and institutional affiliations. 